Artigo Original

\title{
Construção e validação de um instrumento de análise qualitativa do arremesso (lance-livre) do basquetebol ${ }^{1}$
}

\author{
Marcelo Eduardo de Souza Nunes \\ Paula Regina Gehring \\ Luciano Basso \\ Maria Cecília Oliveira da Fonseca \\ Marina Gusman Thomazi \\ Suely Santos \\ Laboratório de Comportamento Motor (LACOM),
Escola de Educação Física e Esporte, Universidade de São Paulo, SP, Brasil
}

\begin{abstract}
Resumo: Quando o profissional da área de Educação Física está ensinando uma habilidade motora, ele procura avaliar o movimento realizado pelo aluno e reflete sobre quais intervenções poderiam ser feitas naquele momento. No entanto, muitas vezes, o professor não dispõe de recursos que possam auxiliá-lo no processo de avaliação do movimento a ser aprendido pelo aluno. O processo de aquisição habilidades motoras poderia ser facilitado se o professor dispusesse nesse momento de um instrumento que identificasse o erro(s) cometido(s), bem como, qual seria a informação prioritária a ser fornecida ao aprendiz. Portanto, como a literatura especializada apresenta escassez no que diz respeito a esse tipo de ferramenta, o objetivo do presente estudo foi construir, validar e testar a objetividade e fidedignidade de um instrumento (checklist) que avalia a qualidade do arremesso do basquetebol (lance livre). O checklist da habilidade foi desenvolvido e avaliado por especialistas da modalidade esportiva e, posteriormente, o checklist foi utilizado para analisar 10 arremessos (vídeo editado) de quatro indivíduos em diferentes fases de aprendizagem da habilidade. Os resultados foram organizados em função do erro crítico e somatória de erros verificados pelos especialistas em duas ocasiões com uma semana de intervalo. Contrastando as avaliações do mesmo avaliador e entre avaliadores, em ambas as medidas, observou-se um nível de erro médio de 16,9\%. Concluiu-se, portanto que o checklist proposto no presente estudo é um instrumento de avaliação do lance livre consistente e, nesse sentido, pode auxiliar professores e técnicos na análise qualitativa do arremesso. Além disso, esse instrumento de avaliação permite fazer inferências sobre o processo de aprendizagem de indivíduos nessa habilidade.
\end{abstract}

Palavras-chave: Arremesso do basquetebol (lance livre). Checklist. Aprendizagem motora.

\section{Development and validation of an instrument to assess movement quality of the basketball free throw shooting}

\begin{abstract}
When a physical activity professional is teaching a motor skill, he evaluates the movement's learner and considers which interventions could be done at the moment. However, many times the instructor does not have such resources which could help him/her to evaluate the learner movement. The skill acquisition process could be facilitated if instructors could have an instrument that identifies errors, prioritizing information to be given to the learner. Considering that the specialized literature presents a lack of information about such tool, the purpose of this study was to develop, and to determine the objectivity and reliability of an instrument to assess the movement quality of the basketball free throw shooting. The checklist was developed and evaluated by basketball experts. Additionally, the checklist was used to assess 10 trials (edited video) from four individuals in different learning stages. Data were organized by the critical error and the error sum appointed by the experts in two different occasions (one week interval). Contrasting both evaluations, and also, contrasting different experts assessments, in sum and critical error, it was observed an average error of $16.9 \%$. It was concluded that the checklist to assess the basketball free throw is reliable, and could help instructors to make a qualitative analysis. Moreover, the checklist may allow instructors to make assumptions on the motor learning process.
\end{abstract}

Keywords: Basketball free throw shooting. Checklist. Motor learning.

${ }^{1}$ Este trabalho é parte integrante da dissertação de mestrado realizada na Escola de Educação Física e Esporte da Universidade de São Paulo, aprovada pelo Comitê de Ética e Pesquisa no CEP/0122010/EEFE/26032010, sob o título de: Efeito da frequência de conhecimento de performance na aprendizagem motora de idosos.

\section{Introdução}

Durante o processo de ensino aprendizagem, uma das muitas funções do professor ou técnico é fornecer feedback extrínseco para o aprendiz ou 
atleta a respeito do seu desempenho na tarefa motora (LEE et al., 1993; SCHMIDT; WRISBERG, 2001). Basicamente, professores e técnicos procuram prover aos seus alunos informações para que eles possam aprimorar o desempenho e atingir a meta da tarefa na tentativa subsequente (TZETZIS et al. 1999; WILLIAMS; HODGES, 2005).

Entende-se que o fornecimento de feedback é o procedimento que consiste no provimento de informação a uma pessoa sobre o desempenho ou ação executada por esta, objetivando reorientar ou estimular comportamentos futuros mais adequados. As pesquisas na área de aprendizagem motora têm demonstrado que o feedback é um elemento essencial no processo de aquisição de habilidades motoras e propõe diretrizes para a utilização do feedback em situações de ensino-aprendizagem (TZETZIS et al. 1999). De acordo com Williams e Hodges (2005), o fornecimento de feedback extrínseco assegura um desenvolvimento apropriado da habilidade e influencia a motivação do aprendiz para persistir com a prática, na medida em que o auxilia conhecer a relação entre a meta e a ação do movimento desejado, promovendo a eficiência na aprendizagem, (LEE et al., 1993).

Considerando que há diversos fatores que interagem no ambiente de ensino-aprendizagem (LEE; SOLMON, 1992), professores e técnicos devem buscar estratégias que possam incrementar o desempenho através da melhor utilização de forma quantitativa e/ou qualitativa da informação para a obtenção da meta (TZETZIS et al. 1999).

Uma forma para maximizar a informação é a utilização de uma lista de feedback extrínseco com palavras e/ou frases que caracterizem a essência do que o aprendiz deverá fazer. Utilizando-se desta lista, professores poderiam fornecer feedbacks que iriam direcionar e capacitar o aprendiz a fazer a necessária correção do seu movimento (SCHMIDT; WRISBERG, 2004).

$\mathrm{Na}$ análise qualitativa de determinada habilidade motora, o professor/técnico deve considerar diversos aspectos, além da habilidade propriamente dita. Por exemplo, ao avaliar habilidades específicas de esporte, Lanier (1985) ressaltou a importância de identificar a (a) avaliação do nível de aprendizagem dos elementos teóricos do jogo; (b) a avaliação dos elementos necessários para a competição referente ao comportamento/rendimento do jogador durante situação real de jogo e; como foi mencionado anteriormente, (c) a avaliação do conjunto de ações motoras desenvolvidas no esporte/atividade referente à análise da qualidade do movimento sem a preocupação com o resultado obtido (o número de cestas convertidas). Embora, poderia ser argumentado que a qualidade do movimento executado não deveria ser dissociada da meta pretendida.

No entanto, é consenso que o conhecimento detalhado da habilidade motora é essencial para professores e a utilização de um instrumento de avaliação poderia auxiliar na tarefa de avaliar de forma consistente a execução das habilidades motoras de diferentes alunos. Além disso, a construção de um instrumento de avaliação qualitativa poderia, também, ser utilizado por estudiosos do processo de aprendizagem motora, já que garantiria uma avaliação consistente e confiável da execução de uma habilidade motora.

Dessa forma, com o intuito de desenvolver um instrumento de medida capaz de avaliar de forma qualitativa uma habilidade motora de alta validade ecológica, optou-se pelo arremesso do basquetebol, ou o lance livre. Sendo assim, o objetivo do presente estudo foi de validar e testar a objetividade e fidedignidade de um instrumento de avaliação da habilidade. Talvez seja oportuno destacar que a literatura especializada em Aprendizagem Motora denomina esse tipo de instrumento como checklist, que significa uma lista de checagem de itens que correspondem aos componentes da habilidade a serem qualitativamente avaliados.

Mais especificamente, a confecção do instrumento será norteada pela avaliação do conjunto de ações motoras do arremesso do basquetebol por meio da análise da qualidade do movimento. A escolha desta habilidade específica do basquetebol (lance livre) está relacionada à motivação inerente da habilidade (encestar a bola) que aprendizes em várias faixas etárias demonstram.

\section{Método}

\section{Instrumento de análise (checklist)}

\section{Construção do instrumento}

Para a elaboração do checklist do arremesso do basquetebol, foi realizado um levantamento bibliográfico referente à descrição do padrão de movimento (FERREIRA; DE ROSE JR., 1987; 
GARCHOW; DICKINSON, 1992; AMERICAN SPORT EDUCATION PROGRAM, 1996; PALUBINSKAS, 2004), a partir do qual foram elencados elementos chave para a realização do arremesso bem sucedido, que são:

- Manter o pé correspondente ao braço de arremesso à frente ou os pés paralelos.

- Manter os joelhos flexionados.

- Segurar a bola com a mão de arremesso atrás da bola e a outra mão ao lado da bola.

- Elevar os braços até que o cotovelo, do braço de arremesso, esteja na mesma linha do ombro.

- Apontar o cotovelo e a mão de arremesso para a cesta.

- Manter o olhar voltado para a cesta.

- Lançar a bola estendendo os joelhos, quadril e braços.

- Finalizar o movimento com um flip, isto é, Flexione o punho.

Segundo Almeida (2000), para fins pedagógicos, os fundamentos podem ser divididos em categorias: equilíbrio; cotovelo; olhos; finalização e; orientações. Entretanto, o aspecto que merece ser enfatizado é que o autor propõe uma hierarquia dos componentes da habilidade, que subentende que há uma ordem de importância de correção de erros, no sentido de otimizar a performance. Essa hierarquização de componentes é identificada pela numeração dos itens, onde 1 corresponde ao erro mais grosseiro e 13 está associado ao erro menos grosseiro.

Outro aspecto considerado para a elaboração do checklist foi a brevidade e exatidão da informação, pois segundo Landin (1994), esse cuidado ou rigor na apresentação das informações tornaria $o$ instrumento de medida mais eficiente, na medida em que facilitaria a compreensão das informações pelo aprendiz.

Assim, as informações sobre o erro a ser corrigido derivado da descrição do movimento correto gerou itens ou informações breves com características guiadoras que visaram conduzir o executante em direção à meta proposta. Com base na sugestão de Almeida (2000), as informações ou erros foram organizados partindo da correção (do erro) mais importante a ser feita na próxima tentativa, utilizando-se 13 itens relacionados ao erro a ser corrigido.

\section{Validação do instrumento}

Após a elaboração do checklist, este estudo foi caracterizado por três etapas. Na primeira etapa, três especialistas na modalidade basquetebol, técnicos com experiência reconhecida em diversas categorias do esporte (desde iniciantes até nas categorias adulta, inclusive com experiência no ensino superior na disciplina de basquetebol), foram convidados a responder um questionário, no qual foi solicitada a atribuição de uma nota de 1 a 5 aos critérios estabelecidos no checklist. Mais especificamente, foram avaliados os seguintes aspectos: (1) se o checklist relacionava os itens fundamentais para a execução do arremesso; (2) se o checklist contemplava todos os itens para avaliar um arremesso; (3) se havia correspondência entre os itens do checklist e a avaliação do treinador em relação ao desempenho do aluno/jogador; (4) se o checklist era de fácil aplicação; e (5) se as informações a serem fornecidas para a correção do arremesso eram relevantes para o aluno/jogador.

A segunda etapa se caracterizou pela filmagem de quatro indivíduos praticantes da modalidade basquetebol em diversas fases do processo de aprendizagem, de novato à experiente, que foram convidados a participar do estudo. Os indivíduos foram orientados a realizar 40 arremessos da linha do lance livre da quadra de basquetebol, enquanto eram filmados por duas câmeras SONY. Uma das câmeras foi direcionada apenas para o padrão de movimento (modelo Handycam DCR-H36/Mini-DV) e a outra foi posicionada para filmar o arremesso completo (modelo DCR-TRV340/Super $8 \mathrm{~mm}$ ), ou seja, o padrão de movimento e o resultado do arremesso (se acertou ou não a cesta). Embora o resultado do arremesso, ou a cesta propriamente dita, não seja considerado para a análise qualitativa da habilidade, a imagem completa poderia oferecer uma ideia global da habilidade. Após a filmagem, os vídeos foram editados com dez arremessos de cada participante de forma sequencial para posterior avaliação.

$\mathrm{Na}$ terceira etapa foram convidados outros três especialistas no basquetebol utilizando-se os mesmos critérios adotados para participação dos três primeiros especialistas. Esses técnicos e/ou professores universitários analisaram a filmagem editada dos quatro participantes e, utilizando a ficha de análise de arremessos ou checklist proposto, apontaram as correções no padrão de movimento que deveriam ser feitas após a realização do arremesso. Esta análise foi repetida uma semana após a primeira análise com o intuito de examinar a coerência do avaliador consigo mesmo em relação à primeira análise dos arremessos. 
Posteriormente, com base nas análises intra e inter avaliadores (terceira etapa), foi realizada uma análise complementar para identificar quais foram os erros mais apontados pelos avaliadores. Além disso, verificou-se a quantidade de erros cometidos por cada participante e, a partir disso, foi caracterizado o comportamento dos participantes iniciantes e dos mais experientes. Vale lembrar, que foi considerado o nível de consistência obtido entre as análises intra e inter avaliadores e, dessa forma, optou-se por sortear um avaliador.

Para a análise desses erros, o checklist foi dividido em três partes e foi feita a soma dos erros anotados dos vídeos apresentados de cada participante. Assim os itens contidos no intervalo do item 1 ao 6 foram considerados como erros de posicionamento inicial (erros mais grosseiros), enquanto os itens do intervalo entre o item 7 e 13, foram considerados erros menos grosseiros e, por último, o item 14 que correspondeu ao número de arremessos realizados de forma correta. Dessa forma, foram obtidas quatro medidas: a) somatória dos erros iniciais (1-6); b) somatória dos erros menos grosseiros (7-13); c) somatória geral de erros (1-13); d) somatória dos arremessos corretos (14).

\section{Resultados}

Conforme os critérios de construção e validação apresentados anteriormente elaborouse o checklist apresentado no Quadro 1.

Quadro 1. Checklist para análise qualitativa do arremesso do basquetebol (lance livre).

\begin{tabular}{|c|c|c|}
\hline \multicolumn{3}{|c|}{ CHECKLIST } \\
\hline 01 & $\begin{array}{l}\text { Manter o pé correspondente ao braço de arremesso à frente a uma distância de } \\
\text { aproximadamente a largura dos ombros. }\end{array}$ & \\
\hline 02 & Flexione os joelhos no inicio do movimento. & ( \\
\hline 03 & Posicione a bola à altura do peito. & ( \\
\hline 04 & Alinhe o cotovelo do braço de arremesso com a linha do ombro. & ( \\
\hline 05 & Segure com a mão de arremesso atrás e mão de suporte ao lado da bola. & ( \\
\hline 06 & Coloque a palma da mão de arremesso para cima. & ( \\
\hline 07 & Apoie a bola somente nos dedos. & ( \\
\hline 08 & Aponte o cotovelo do braço de arremesso para cesta. & ( \\
\hline 09 & Olhe para a cesta. & ( \\
\hline 10 & Estenda os joelhos, quadril e eleve os braços estendendo o cotovelo sem pausas. & ( \\
\hline 11 & Aponte os dedos da mão de arremesso para a cesta ao final do arremesso. & ( \\
\hline 12 & Flexione o punho ao final do arremesso. & ( \\
\hline 13 & Faça a bola girar ao contrário ao final do arremesso. & ( \\
\hline 14 & Não cometeu erro. & ( \\
\hline
\end{tabular}

\section{Análise estatística}

Para avaliar a fidedignidade, foi computada a somatória do erro inter e intra-avaliador. $\mathrm{O}$ erro inter-avaliador é a razão do número de casos em que não houve concordância entre os avaliadores sobre o número total de casos. Ao ser multiplicado por 100, têm-se o percentual de casos discordantes entre dois dos avaliadores. Como foram utilizados três avaliadores, optou-se por computar o índice de concordância par a par e depois realizar a média dos três índices para obter o erro inter-avaliador geral. Para o erro intraavaliador foi calculado a razão do número de casos em que não houve concordância do avaliador com ele mesmo após uma semana de intervalo (teste e reteste). O nível de erro geral do instrumento foi expresso pela soma do erro interavaliador e do erro intra-avaliador, que segundo
Anastasi e Urbina (2000) torna-se aceitável quando fica próximo a $20 \%$. Esses cálculos foram realizados para a variável erro crítico e o número total de erros apontados.

Inicialmente foram analisadas as respostas obtidas no questionário respondido pelos especialistas quanto à elaboração do checklist que foi utilizado na primeira etapa do estudo. A utilização de uma escala de 1 a 5 para cada questão possibilitou a utilização da escala de Likert que consiste de um número igual de condições de respostas, de favorável a não favorável, na qual os participantes ou respondentes são orientados a escolher uma das cinco possíveis respostas desta relação: 5 concordo plenamente, 4 - concordo, 3 - indeciso, 2 - discordo e 1 - discordo plenamente (SAFRIT; WOOD, 1989). 
Os valores médios obtidos (ver Tabela 1) nas respostas dos especialistas que avaliaram 0 checklist foram, respectivamente, 4,00; 4,30; 4,30; 4,30; e 5,00. De um modo geral, esses resultados indicam que os especialistas concordam com a proposta do checklist. Especificamente, o item que avaliou se o checklist se relaciona com os aspectos fundamentais para a execução do arremesso, recebeu o escore 4, o que demonstra que os especialistas estão de acordo com o conteúdo do checklist proposto. Os demais itens que indicam se o checklist contempla todos os itens para se avaliar um arremesso, se há correspondência entre os itens do checklist e a avaliação do treinador/especialista em relação ao desempenho do aluno/jogador e se o checklist era de fácil aplicação, receberam o escore médio de 4,30. Este resultado permite afirmar que os especialistas concordam que as informações contidas no checklist são pertinentes e que ao utilizá-lo é possível avaliar a execução do arremesso e, também, que pode auxiliar o professor na avaliação do desempenho do aluno/jogador, além de ser de fácil utilização/aplicação. $O$ item que questionou se as informações a serem fornecidas para a correção do arremesso eram relevantes para 0 aluno/jogador, recebeu o escore máximo 5 , ou seja, pode-se afirmar que os especialistas concordaram plenamente que as informações (feedback) contidas no checklist são relevantes para o aluno/jogador.

Tabela 1. Respostas dadas pelos avaliadores para cada item do questionário a partir da utilização da escala de Likert.

\begin{tabular}{|c|c|c|c|c|c|c|c|c|c|c|c|c|c|c|c|c|c|}
\hline & \multicolumn{5}{|c|}{ AVALIADOR A } & \multicolumn{5}{|c|}{ AVALIADOR B } & \multicolumn{5}{|c|}{ AVALIADOR C } & \multirow{2}{*}{$\begin{array}{c}\text { MÉDIA } \\
\text { DOS } \\
\text { AVAL. }\end{array}$} \\
\hline & \begin{tabular}{|l|} 
ESCALA \\
DE LIKERT \\
\end{tabular} & 1 & 2 & 3 & 4 & 5 & 1 & 2 & 3 & 4 & 5 & 1 & 2 & 3 & 4 & 5 & \\
\hline \multirow{5}{*}{ 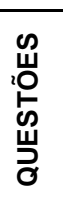 } & $A$ & & & & 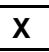 & & & & & $\mathbf{X}$ & & & & & $\bar{x}$ & & 4,0 \\
\hline & $B$ & & & & & $\mathbf{X}$ & & & & $x$ & & & & & $x$ & & 4,3 \\
\hline & $C$ & & & & $\mathbf{X}$ & & & & & & $\mathbf{X}$ & & & & $\mathbf{X}$ & & 4,3 \\
\hline & $D$ & & & & $x$ & & & & & $x$ & & & & & & 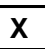 & 4,3 \\
\hline & $E$ & & & & & $\mathbf{X}$ & & & & & $\bar{x}$ & & & & & $\mathbf{X}$ & 5,0 \\
\hline
\end{tabular}

O nível de erro intra-avaliador para a medida de erro crítico foi de $5,4 \%$, enquanto que para a comparação inter-avaliadores o nível de erro foi de 11,5\%, como pode ser visto nas Tabelas 2 e 3. Portanto, o nível de erro geral da medida de erro critico foi $16,9 \%$, configurando-se como aceitável, segundo Anastasi e Urbina (2000).

Tabela 2. Nível de erro (\%) intra-avaliador na avaliação teste-reteste relativa erro crítico apontado pelos avaliadores especialistas do arremesso do basquetebol (lance livre).

\begin{tabular}{c|c}
\hline $\begin{array}{c}\text { Erro } \\
\text { Intra-avaliador }\end{array}$ & $\begin{array}{c}\text { \% de erro } \\
\text { (teste-reteste) }\end{array}$ \\
\hline Avaliador 1 & 5,6 \\
\hline Avaliador 2 & 6,9 \\
\hline Avaliador 3 & 3,8 \\
\hline Média & 5,4 \\
\hline
\end{tabular}

Tabela 3. Nível de erro (\%) inter-avaliador na avaliação teste-reteste relativa erro crítico apontado pelos avaliadores especialistas do arremesso do basquetebol (lance livre).

\begin{tabular}{c|c}
\hline $\begin{array}{c}\text { Erro } \\
\text { Inter-avaliador }\end{array}$ & $\begin{array}{c}\% \text { de erro } \\
\text { (teste-reteste) }\end{array}$ \\
\hline $1 \times 2$ & 13,8 \\
\hline $1 \times 3$ & 7,5 \\
\hline $2 \times 3$ & 13,1 \\
\hline Média & 11,5 \\
\hline
\end{tabular}

No que diz respeito ao grau de erro relativo à somatória de erros apontados pelo mesmo avaliador (intra-avaliador), a média foi $6,2 \%$. O erro inter-avaliadores foi $11,2 \%$. As Tabelas 4 e 5 ilustram essas comparações. Portanto, o nível de erro geral da medida somatória de erros foi $17,4 \%$, configurando-se como aceitável (ANASTASI; URBINA,2000).

Tabela 4. Nível de erro (\%) intra-avaliador na avaliação teste-reteste relativa à somatória de erros apontados pelos avaliadores especialistas do arremesso do basquetebol (lance livre).

\begin{tabular}{c|c}
\hline $\begin{array}{c}\text { Erro } \\
\text { Intra-avaliador }\end{array}$ & $\begin{array}{c}\text { \% de erro } \\
\text { (teste-reteste) }\end{array}$ \\
\hline Avaliador 1 & 5,0 \\
\hline Avaliador 2 & 7,5 \\
\hline Avaliador 3 & 6,3 \\
\hline Média & 6,2 \\
\hline
\end{tabular}

Tabela 5. Nível de erro (\%) inter-avaliador na avaliação teste-reteste relativa à somatória de erros apontados pelos avaliadores especialistas do arremesso do basquetebol (lance livre).

\begin{tabular}{c|c}
\hline $\begin{array}{c}\text { Erro } \\
\text { Inter-avaliador }\end{array}$ & $\begin{array}{c}\% \text { de erro } \\
\text { (teste-reteste) }\end{array}$ \\
\hline $1 \times 2$ & 13,8 \\
\hline $1 \times 3$ & 8,1 \\
\hline $2 \times 3$ & 11,9 \\
\hline Média & 11,2 \\
\hline
\end{tabular}


Tabela 6. Somatória dos erros cometidos por cada participante a partir da análise de vídeo e utilização do checklist.

\begin{tabular}{|c|c|c|c|c|c|}
\hline & \multirow{2}{*}{$\begin{array}{c}\text { ITENS } \\
\text { CHECKLIST }\end{array}$} & \multicolumn{4}{|c|}{ AVALIADOR } \\
\hline & & SUJ A & sus $B$ & sus C & SUJ D \\
\hline \multirow{14}{*}{ 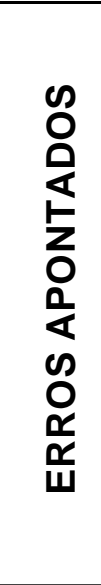 } & 1 & 2 & 0 & 1 & 0 \\
\hline & 2 & 2 & 2 & 0 & 0 \\
\hline & 3 & 5 & 2 & 1 & 0 \\
\hline & 4 & 6 & 4 & 1 & 0 \\
\hline & 5 & 5 & 4 & 0 & 0 \\
\hline & 6 & 6 & 4 & 0 & 0 \\
\hline & 7 & 2 & 1 & 2 & 4 \\
\hline & 8 & 7 & 5 & 2 & 2 \\
\hline & 9 & 2 & 0 & 0 & 0 \\
\hline & 10 & 6 & 5 & 6 & 3 \\
\hline & 11 & 5 & 6 & 6 & 5 \\
\hline & 12 & 10 & 10 & 5 & 5 \\
\hline & 13 & 10 & 10 & 5 & 4 \\
\hline & 14 & 0 & 0 & 5 & 6 \\
\hline \multicolumn{2}{|c|}{ Soma Erros Básicos } & 28 & 17 & 5 & 4 \\
\hline \multicolumn{2}{|c|}{ Soma Erros Execução } & 40 & 36 & 24 & 19 \\
\hline \multicolumn{2}{|c|}{ Soma Geral Erros } & 68 & 53 & 34 & 29 \\
\hline \multicolumn{2}{|l|}{ Acertos } & 0 & 0 & 5 & 6 \\
\hline
\end{tabular}

A análise de somatória dos erros (Tabela 6), realizada com o intuito de caracterizar os erros apontados pelos avaliadores durante a fase de visualização dos vídeos, mostrou que na soma geral dos erros apontados pelo avaliador, o participante $A$ foi o que cometeu mais erros, seguido do participante $B, C$ e $D$ respectivamente. A soma dos erros de posicionamento inicial (itens 1 ao 6) e a soma dos erros considerados menos grosseiros (itens 7 ao 13) apontou que os participantes $A$ e $B$, menos experientes, cometeram mais erros que estão relacionados com a posição inicial do movimento quando comparados com os participantes $C$ e $D$ com maior tempo de prática na modalidade basquetebol. Ao comparar a soma dos erros apontados nos itens finais do checklist observouse que esse comportamento se repete, sendo que, o participante $D$ foi quem cometeu menos erros, seguido do participante $C$. No que se diz respeito ao apontamento de acertos (item 14), apenas os participantes $D$ e $C$ receberam apontamentos nesse item.

\section{Discussão}

De um modo geral, o objetivo deste estudo foi construir e validar um checklist de avaliação do arremesso do basquetebol (lance livre), examinando a objetividade (erro inter-avaliador) e a fidedignidade (erro intra-avaliador) do instrumento. Potencialmente, essa avaliação qualitativa do padrão de movimento poderia ser utilizada, inclusive, para inferir a aprendizagem da habilidade. A confecção do checklist considerou o que foi afirmado por Knudson e Morrison (2002), isto é, que uma "boa frase" comunica a essência de fatores críticos de forma concisa e auxilia o aprendiz a relembrar tais fatores durante a prática. Desta forma, foi elaborado um checklist, cuja descrição do movimento foi baseada na literatura especializada e os elementos chave para a realização do arremesso de forma correta foram elencados de forma hierárquica.

A escala de Likert utilizada para avaliar os critérios estabelecidos na elaboração do mesmo, bem como o conteúdo, mostrou que entre os cinco critérios avaliados, os especialistas estão de acordo em relação ao conteúdo do checklist (itens fundamentais para a execução do arremesso, a aplicabilidade, e a avaliação do professor) e concordam plenamente (segundo a escala de Likert) que a lista de feedbacks que fazem parte deste checklist é importante para auxiliar a aprendizagem do arremesso.

O checklist foi elaborado baseando-se em uma hierarquia, ou ordem crescente de prioridade, ou seja, partindo da correção mais importante a ser feita na próxima tentativa. A fidedignidade desse instrumento de avaliação (teste-reteste) examinou se os avaliadores especialistas concordam em relação ao erro crítico, bem como concordam em relação à somatória de erros para cada vídeo analisado. O grau de erro geral abaixo de $20 \%$ em relação ao erro crítico demonstrou que os avaliadores anotaram o mesmo erro como sendo o primeiro de uma lista de 14 itens e permitiu a observação da consistência na opinião dos avaliadores em relação ao erro mais grosseiro.

Para a análise da somatória de erros, o objetivo foi observar se ao analisar o vídeo, os avaliadores apontavam um número semelhante de erros cometidos pelo indivíduo avaliado, nas dez tentativas. Esta comparação teste-reteste quanto ao nível de erro geral não ultrapassou os $20 \%$. Esses valores demonstram que dentre o número total de erros possíveis a serem apontados pelos avaliadores especialistas, houve uma precisão considerável na análise. Isto porque, como foi descrito por Anastasi e Urbina (2000), a precisão se refere à "consistência dos escores obtidos pelas mesmas pessoas quando elas são examinadas com o mesmo teste em 
diferentes ocasiões, ou com diferentes conjuntos de itens equivalentes, ou sob outras condições variáveis do exame", condições estas contempladas pelos avaliadores que participaram deste estudo.

Em relação à análise complementar, que identificou os erros mais apontados pelos avaliadores, bem como, quantificou os erros cometidos por cada participante, mostrou que, como esperado, os participantes com menos tempo de prática cometeram mais erros na soma geral, em especial os erros considerados mais grosseiros (1-6). Quando se observou apenas o comportamento dos indivíduos $A$ e $B$, pode-se notar que 0 indivíduo $B$ cometeu menos erros grosseiros quando comparado o indivíduo $A, 0$ que evidencia que, embora iniciantes, o indivíduo $B$ pode ser considerado, aparentemente, mais experiente do que o indivíduo $A$. O mesmo ocorre quando comparamos os indivíduos $C$ e $D$. Notase que o indivíduo $D$ cometeu menor número de erros considerados menos grosseiros e também executou um maior número de arremessos considerados corretos pelo avaliador. Dessa forma, o checklist auxiliou não só os avaliadores na detecção dos erros cometidos pelos participantes, mas também auxiliou na caracterização dos erros e, consequentemente, na identificação mais detalhada do nível de experiência de cada participante.

Esses resultados mostraram que o checklist parece ser um instrumento útil no processo ensino-aprendizagem, em especial, na avaliação do nível de experiência de um aluno/atleta. Esta particularidade do checklist, por si só, pode auxiliar profissionais ou pesquisadores, pois conforme descrito por Santos (2005), a diferença entre um indivíduo iniciante e um experiente em uma determinada habilidade motora pode ser óbvia para muitos observadores, porém mensurar essa diferença pode não ser tarefa simples, já que movimentos são surpreendentemente difíceis de medir, na medida em que a habilidade motora envolve a coordenação e controle de movimentos entre membros e tronco, de acordo com a demanda exigida pelo tempo e o espaço. Adicionalmente, Safrit e Wood (1989) afirmam que, é de suma importância para os professores determinar o grau de como a aprendizagem está ocorrendo, avaliar e discriminar adequadamente os diversos níveis de habilidade dos aprendizes e, para tanto, um checklist da habilidade poderia auxiliar nesse processo.
No que diz respeito à aplicabilidade do checklist, Nunes (2010) utilizou-se desse mesmo instrumento para avaliar o desempenho de 60 indivíduos com idade média de 64,2 anos, sem experiência com basquetebol, com 0 intuito de inferir a aprendizagem da habilidade. Nesse estudo, foi solicitado aos participantes realizar o arremesso do lance livre e após a execução do arremesso foi fornecido feedback extrínseco sobre 0 que o participante deveria fazer na próxima tentativa para corrigir o arremesso, em um total de 90 tentativas. Essa informação foi fornecida com base no checklist utilizando como critério o erro crítico. O erro crítico foi definido como o primeiro erro apontado no checklist, uma vez que o critério prioridade foi utilizado para a ordenação dos itens.

O autor considerou duas medidas de desempenho, uma medida qualitativa e uma medida quantitativa. A medida qualitativa expressou a qualidade do arremesso do basquetebol ao longo da aprendizagem, por meio dos itens hierárquicos do checklist (erro crítico) observado em cada uma das noventa tentativas realizadas pelos participantes. A medida quantitativa expressou 0 resultado da ação (obtenção da cesta), por meio do escore obtido (zero ou um).

A associação entre o padrão de movimento do arremesso utilizado pelos idosos e a quantidade de acertos na cesta foi avaliada com uma correlação de $r=0,762$. Esse resultado demonstrou que na medida em que os idosos aperfeiçoavam o padrão de movimento e recebiam as informações contidas no checklist, se aproximavam do item de número 14 (movimento correto), eles acertaram a cesta com maior frequência.

Esses resultados corroboram as afirmações de Weiss (1983), que afirmou que fornecer aos aprendizes que possuem um reduzido ou nenhum conceito a respeito da habilidade a ser praticada, informações relacionadas ao seu padrão de movimento pode guiar e desenvolver uma técnica correta de execução da habilidade motora.

Assim sendo, a partir das análises realizadas no presente estudo conclui-se que o instrumento proposto pode auxiliar professores e técnicos na análise qualitativa do arremesso do basquetebol (lance livre) de indivíduos em diferentes fases do processo de aprendizagem da habilidade e, 
consequentemente, otimizar 0 processo de aprendizagem do arremesso do lance livre.

Além disso, a uso do checklist na avaliação do desempenho permite fazer inferências sobre 0 processo de aprendizagem dessa habilidade, o que possibilita a sua utilização por pesquisadores do comportamento motor, pois proporciona uma medida consistente e confiável da habilidade, particularmente, quando o interesse estiver na utilização de tarefas de maior validade ecológica como é o lance livre do basquetebol, por se aproximarem do chamado mundo real e proporcionarem maior significado à prática dos indivíduos.

$\mathrm{Na}$ literatura especializada há certa carência desse tipo de instrumento de análise, dessa forma, o instrumento proposto oferece suporte a futuras pesquisas, que a partir da metodologia empregada pode vir a elaborar instrumentos sensíveis na detecção de erros, aqueles considerados mais sutis. Neste caso, os indivíduos carecem de correções para que um nível superior de desempenho seja atingido e, de acordo com Weiss (1983), como o indivíduo habilidoso já possui um grande repertório à sua disposição durante a realização de uma tarefa, informações a respeito do seu padrão de movimento poderiam auxiliar a tomada de decisão. Isto ocorreria porque essas informações poderiam reduzir o número de respostas a serem escolhidas, levando o aprendiz em estágio avançado, em condições de selecionar rapidamente a melhor resposta para resolver o problema.

Considerando o exposto, é possível vislumbrar potenciais aplicações desse conhecimento: 1) avaliar aprendizes de diferentes níveis de desempenho na modalidade basquetebol por professore/técnicos; 2) verificar a aquisição da habilidade por professore/técnicos e pesquisadores; 3) examinar os fatores que influenciam a aprendizagem motora por pesquisadores; 4) auxiliar no processo de elaboração de um instrumento de avaliação de outras habilidades motoras.

No entanto, algumas limitações devem ser levadas em consideração, dentre elas, o fato de que, para fazer uso do checklist o professor deve ter um conhecimento prévio sobre o arremesso do lance livre, bem como, saber identificar possíveis erros cometidos durante a execução por parte do aprendiz. Adicionalmente, instrumento ora proposto deve ser utilizado para avaliar praticantes com pouco ou nenhum tempo de experiência no basquetebol, já que praticantes mais experientes necessitariam de informações mais refinadas.

Finalmente, outra limitação do instrumento proposto pode estar relacionada ao número de especialistas que participaram no processo de construção, pois seis especialistas (técnicos/professores universitários de basquetebol) participaram desse processo de desenvolvimento do instrumento de avaliação, muito embora o critério de seleção e inclusão desses especialistas no presente estudo, tenha levado em consideração a experiência prévia desses profissionais em categorias de base do basquetebol, equipe adulta participante de campeonato estadual de basquetebol e ainda a experiência como docente na disciplina de basquetebol atuando na formação de professores de Educação Física.

\section{Referências}

ALMEIDA, M. B. Basquetebol: iniciação. Rio de Janeiro: Sprint, 2000.

ANASTASI, A.; URBINA, S. Testagem

psicológica. Porto Alegre: ArtMed Editora, 2000.

AMERICAN SPORT EDUCATION PROGRAM.

Coaching youth Basketball. Champaign: Human Kinetics, 1996.

FERREIRA, A. E. X.; DE ROSE JR, D.

Basquetebol: Técnica e Táticas - uma abordagem didático-pedagógica. São Paulo: EPU/EDUSP, 1987.

GARCHOW, K.; DICKINSON, A. Youth

Basketball: A complete handbook. EUA: Cooper Publishing Group, LLC, 1992.

KNUDSON, D. V.; MORRISON, C.S. Qualitative Analysis of Human Movement. Second Edition, Champaign: Human Kinetics, 2002.

LANDIN, D. The role of Verbal Cues in Skill Learning. Quest, Tucson, 46 p. 299-313, 1994.

LANIER, A. S. Los tests pedagógicos en el deporte de alto rendimiento. Stadium, Italy, v.19, n.113, p. 45-46, 1985. 
LEE, A. M.; SOLMON, M. A. Cognitive

conceptions of teaching and learning motor skills. Quest, Tucson, v.44, p.55-71, 1992.

LEE, A. M.; KEH, N. C.; MAGILL, R. A. Instructional effects of teacher feedback in physical education. Journal of Teaching in Physical Education, Champaign, v.12, p.228243, 1993.

NUNES, M. E. S. Efeito da frequência de conhecimento de performance na aprendizagem motora de idosos. 2010. $110 \mathrm{f}$. Dissertação (Mestrado em Ciências da Biodinâmica do Movimento Humano) - Escola de Educação Física e Esporte, Universidade de São Paulo, São Paulo.

PALUBINSKAS, E. D. The jump shot. In: Coaches - fundamentals and youth basketball. FIBA Assist Magazine, Geneva, p.06-11, 2004.

SAFRIT, J. M.; WOOD, T. M. Measurement concepts in physical education and exercise science. Champaign: Human Kinetics Books, 1989.

SANTOS, S. Habilidade motora e envelhecimento In G. Tani (Ed.), Comportamento motor: aprendizagem e desenvolvimento. Rio de Janeiro: Guanabara Koogan, p.173-84, 2005.

SCHMIDT, R. A.; WRISBERG, C. A. Motor Learning and Performance: A problem-based learning approach. Third Edition, Champaign: Human Kinetics, 2004.

SCHMIDT, R. A.; WRISBERG, C. A. Aprendizagem e Performance Motora: uma abordagem da aprendizagem baseada no problema. 2º Edição, Porto Alegre: ArtMed, 2001.

TZETZIS, G.; KIOUMOURTZOGLOU, E.; LAIOS, A.; STERGIOU, N. The effect of different feedback models on acquisition and retention of technique in basketball. Journal of Human Movement Studies, New York, v. 37, p. 163-181, 1999.

WEISS, M R. Modeling and motor performance: A developmental perspective. Research Quarterly for Exercise and Sport, Washington, v.54, p.19097, 1983.

WILLIAMS, A. M.; HODGES, N.J. Practice, instruction and skill acquisition in soccer: Challenging tradition. Journal of Sports Sciences, London, v.23, n.6, p.637-50, June 2005.
Agradecimentos: Os autores agradecem a colaboração dos professores e técnicos especialistas cujas sugestões e participação foram fundamentais para a realização desse estudo.

\section{Endereço:}

Marcelo Eduardo de Souza Nunes LACOM- E.E.F.E. / Universidade de São Paulo. Av. Prof. Melo de Morais, 65 Cidade Universitária São Paulo SP Brasil 05508-030

Telefone: (11) 8166-3643

e-mail: nunesme@usp.br

Recebido em: 30 de janeiro de 2011. Aceito em: 2 de julho de 2012.

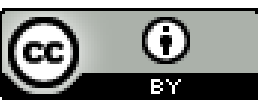

Motriz. Revista de Educação Física. UNESP, Rio Claro, SP, Brasil - elSSN: 1980-6574 - está licenciada sob Creative Commons - Atribuição 3.0 